the wound may continue for up to 14 days and movement of the limb can be greatly restricted. ${ }^{2}$

A broad array of systemic symptoms may accompany envenomation. The victim may be agitated, pale, or anxious and headaches, nausea, vomiting, sweating, and syncope may occur rarely. There is a case report of a six week pregnant woman who developed vaginal bleeding immediately after a weever fish envenomation and three weeks later spontaneously aborted the fetus. ${ }^{8}$

Management of a weever fish sting should be to immerse the affected limb or wound promptly in hot water (approximately $40^{\circ} \mathrm{C}$ or as hot as can be tolerated) for about 20 minutes, though care should be taken to avoid scalding. If immersion is not possible, hot soaks or a poultice should be applied. ${ }^{7}$ This will dramatically ease the pain within a few minutes, as the toxin is thermolabile. Cold application worsens the pain. ${ }^{9}$ Usually, simple analgesics will relieve residual pain but on occasions opiate analgesia may be required. Injection of local anaesthetic, either by infiltration or by regional nerve block, may also be considered. Intravenous calcium gluconate has been found to be effective in relieving pain in a case where intravenous narcotics failed. ${ }^{10}$ Local wound toilet, debridement, and tetanus prophylaxis are provided as necessary. The spines only rarely embed in the tissue. ${ }^{27}$
Infection is rare but antibiotics will be necessary if local infection develops, and can be considered for prophylaxis in the immunocompromised patient. Antihistamines may relieve the local inflammatory response. Otherwise treatment is supportive. Occasionally, envenomation will be accompanied by an allergic reaction and treatment for anaphylaxis will be necessary. ${ }^{10}$ Prevention is primarily by avoidance, wearing sufficient protective footwear, and never handling weever fish. ${ }^{11}$

I wish to thank $\mathrm{Mr}$ Gordon Howes for his advice and his drawing of the lesser weever fish.

1 Cain D. Weever fish sting: an unusual problem. $B M \mathcal{F}$ $1983 ; 287: 406-7$

The stinging Weever fishes. Practitioner

1975;215:223-5.
3 Gonzaga RAF. Venomous fish stings on the European seashore. Postgrad Med 1985;77:146-8.

4 Ellenhorn MJ, Barceloux DG Medical toxicology: diagnosis and treatment of human poisoning 1st ed Amsterdam:

5 Chhatwal I, Dreyer F. Isolation and characterization of dracotoxin from the venom of the Greater Weever fish Trachinus draco. Toxicon 1992:30:87-93.

6 Viccellio P. Handbook of medical toxicology, 1st ed. Boston: Little, Brown, 1993.

7 Briars GL, Gordon GS. Envenomation by the Lesser Weever fish. Br $\mathcal{F}$ Gen Pract 1992;42:213.

8 Gonzago RAF. Spontaneous abortion after a Weever fish

sting. $B M \mathcal{F} 1985 ; 290: 518$.
9 Russell $\mathrm{FE}$. Weever fish sting: the last word. $B M \mathcal{F} 1983$; 287:981-2.

10 McGoldrick J, Marx JA. Marine envenomations. Part 1. Vertebrates. F Emerg Med 1990;9:497-502.

11 Brown CK, Shepherd SM. Marine trauma, envenomations and intoxications. Emerg Med Clin North Am 1992;10: 385-408.

\title{
Lumps, bumps and soft tissue sarcomas
}

\author{
Sean J McGovern
}

\begin{abstract}
A case of soft tissue sarcoma in a young person is described. Accident and emergency workers should be aware of this highly malignant group of tumours. Lumps in young people should not necessarily be assumed to be benign without a definite histological diagnosis.
\end{abstract}

(f Accid Emerg Med 1996;13:141-142)

Key terms: soft tissue sarcoma; diagnosis

Soft tissue sarcomas are a diverse group of uncommon neoplasms representing less than $1 \%$ of cancer admissions to hospital. ${ }^{1}$ The prevalence of these tumours in Ireland is thought to be similar to that in North America, that is, 2 per 100000 of population. ${ }^{2}{ }^{3}$ There have been reports of an increase in these tumours in a number of western countries; however, preliminary evidence suggests that this increase may be due to the increase in Kaposi's sarcoma in AIDS patients. ${ }^{45}$ Those who work in primary care or in accident and emergency medicine need to consider these uncommon tumours in the differential diagnosis of any soft tissue mass, as they are highly malignant and can simulate a benign process, especially in the young.

\section{Case report}

$\mathrm{KW}$, an 18 year old Chinese student, attended an accident and emergency (A\&E) department complaining of a painless $2 \mathrm{~cm} \times 2 \mathrm{~cm}$ lump on the medial aspect of his left thigh for three weeks. The patient was reassured that it was a benign lump. Seven months later he presented to another $\mathrm{A} \& \mathrm{E}$ department complaining of a marked increase in size of the lump over the previous few days, associated with pain. On examination there was a $14 \mathrm{~cm} \times 6 \mathrm{~cm}$ swelling on the medial aspect of his left thigh. It was tender to touch and fixed to the muscle with overlying skin changes. The patient was going to Hong Kong for two months and he refused admission. He was advised to seek urgent medical attention while in Hong Kong.

On return two months later he attended surgical outpatients. He was noted to have an $18 \mathrm{~cm} \times 6.5 \mathrm{~cm}$ hard craggy mass on the 
medial aspect of his left thigh. No inguinal lymphadenopathy was detected. Fine needle aspiration was inconclusive; however, open biopsy revealed a spindle cell synovial sarcoma of high grade malignancy. Chest $x$ ray revealed three opacities which computerised tomography (CT) scanning confirmed to be secondary deposits.

A CT scan of his left thigh showed a fixed attenuated mass on the medial aspect of his left thigh but no bony infiltration or destruction.

Because of the poor prognosis and to avoid mutilating amputation a debulking procedure was performed. The patient received combination radiotherapy and chemotherapy but died nine months after initial diagnosis.

\section{Discussion}

Synovial sarcoma forms about $2 \%$ of soft tissue sarcomas. ${ }^{4}$ The most common manifestations of these tumours are swelling and pain. Some patients attribute the swelling to a minor injury which can cause them to delay a visit to a physician; however, it is most likely that minor injury brings the lesion to the attention of the patient. Another source of delay in diagnosis is the presumption by the examining physician that the growth is benign, for example a lipoma in this patient. The sudden increase in size of the tumour is due to haemorrhage.

Whereas reassurance plays an important part in the many lumps and bumps that present to the primary care physician or the $A \& E$ department, it is imperative that an adequate histological diagnosis is made of lesions which continue to grow, do not resolve after 3-4 weeks, or are atypical, especially those on the lower limbs of young people. Patients discharged from the A\&E department must be given a clear management plan if the above conditions exist.
An incisional biopsy is usually the appropriate diagnostic procedure. Needle aspiration cytology gives inadequate material for correct histopathological classification but Trucut biopsy may provide adequate material for a diagnosis. ${ }^{6}$ If a sarcoma is suspected, the patient should be referred to a surgeon who is experienced in such techniques. Most centres dealing with soft tissue sarcomas prefer imaging with CT or magnetic resonance imaging before biopsy.?

The five year survival rate in soft tissue sarcomas is better than $45 \%$; however, there is need for early detection and for vigilance on the part of the examining physician. Multivariate analysis has identified only high grade of malignancy and an increase in tumour size as independent prognostic indicators in soft tissue sarcoma. ${ }^{8} 9$

1 Boring CC, Squires TS, Montgomery S, Tong T. Cancer statistics, 1994. Cancer f Clin 1994;44:7-26.

2 Gaffney EF, Dervan PA, Kelly PM, McCabe MM, Leader $M$. Soft tissue and visceral sarcomas in Irish patients. A preliminary report from the Dublin Soft Tissue Tumour panel. Irish F Med $S_{c i} 1991 ; 160 \cdot 247-8$.

3 Enzinger FM, Weiss SW Soft tissue tumors. St Louis: C V Mosby, 1988.

4 Schuurman B, Meyer S, Cuesta MA, Nauta JJ. Increasing frequency of soft tissue sarcomas in The Netherlands. frequency of soft tissue sarcomas in The Netherlands. Nederlands
[in Dutch].

[in Dutch].
5 Ross JA, Severson RK, Davis S, Brooks JJ. Trends in the incidence of soft tissue sarcoma in the United States from incidence of soft tissue sarcoma in the United

6 Munk PI, Vellet AD, Bramwell V, Bell R, Hammond A, Munk PI, Vellet AD, Bramwell V, Bell R, Hammond A, Beauchamp C. Soft tissue sarcoma: a plea

7 Ruka W, Emrich LJ, Driscoll DL, Karakousis CP. Prognostic significance of lymph node metastatis and bone, major vessel or nerve involement in adults with high grade soft tissue sarcomas. Cancer 1988;62:999-1006.

8 Weingrad DN. Rosenberg SA. Early lymphatic spread of osteogenic and soft tissue sarcomas. Surgery 1978;84: $231-40$.

9 Rydholm A, Gustafson P, Rooser B, Willen H, Berg NO Subcutaneous sarcoma. A population-based study of 129 patients. F Bone foint Surg Br 1991;73:662-7. 